Original Article

\title{
PREVALENCE OF UNDIAGNOSED POST TRAUMATIC STRESS DISORDER AMONG IN-PATIENTS IN A SUBSTANCE USE DISORDER TREATMENT CENTRE IN NIGERIA
}

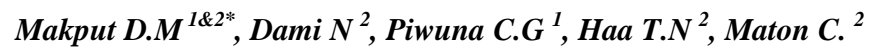 \\ Department of Psychiatry, Jos University Teaching Hospital ${ }^{l}$ and Centre for Addiction Treatment and Research, Vom, Jos, Plateau State ${ }^{2}$.
}

\begin{abstract}
*Corresponding Author: Dr D.M Makput, Department of Psychiatry, Jos University Teaching Hospital, PMB 2076, Jos, Plateau State, Nigeria. Email: harrymakput@yahoo.co.uk
\end{abstract}

Received date: April $23^{\text {rd }} 2018$, Accepted date: June $5^{\text {th }}$ 2018. Published date: June $30^{\text {th }} 2018$

\begin{abstract}
Post traumatic stress disorder is a clinical disorder characterized by emotional and physical symptoms that may occur after exposure to a severely traumatic event. It occurs commonly as a co-morbid diagnosis with substance related disorders, as well as other psychiatric disorders. We postulated that post traumatic stress disorder may be under- diagnosed in therapeutic wards where substance use disorders are treated. This study thus sought to determine the prevalence of undiagnosed post traumatic stress disorder in a substance use disorder in-patient population. The posttraumatic stress disorder check list, Civilian version was administered to patients on admission at the Center for addiction treatment and research, Vom, Plateau state, Nigeria in June 2017. Sociodemographic data and information regarding substance use were also obtained from the patients. A total of 38 inpatients were analyzed and $8(21 \%)$ met the Diagnostic and statistical manual of mental disorders (fourth edition) criteria for current post traumatic stress disorder. None of the patients had a diagnosis of post traumatic stress disorder in their case notes prior to the post traumatic stress disorder check list administration in this study. Post traumatic stress disorder which is frequently co-morbid with substance abuse remains undiagnosed in many patients admitted to our therapeutic center.
\end{abstract}

Keywords: In-patients, Nigeria, Post-traumatic stress disorders, Substance use disorder, Undiagnosed.

\section{Introduction}

Post Traumatic Stress Disorder (PTSD) is a psychological disorder in which there is a delayed and/or protracted response to a stressful event or situation of an exceptionally threatening or catastrophic nature which is likely to cause pervasive distress in almost anyone. ${ }^{1}$ It was initially referred to as ' $\mathrm{Da}$ Costa Syndrome after the American internist Jacob Mendez Da Costa (1833-1900). Da Costa ${ }^{2}$ reported in 1871 that this disorder is most commonly seen in soldiers during times of stress, especially when fear was involved.

People who witness or were involved in events that are exceptionally life threatening can develop PTSD. The clinical features of this disorder may begin soon after the event but sometimes much later about six months and include insomnia, exaggerated startle response, intensive imagery (flashback), smell or sound associated with the event and avoidance of reminders of the event. ${ }^{3}$ The prevalence of current PTSD in Substance Use Disorder (SUD) patients is about three times higher than in the general population, ranging from $25.3 \%$ to $49 \%$. $^{4,5}$

Studies of both combat veterans and civilians with PTSD have demonstrated that, among men with PTSD, alcohol abuse or dependence is the most common co-occurring disorder, followed by depression then other anxiety disorders. ${ }^{6}$ PTSD and substance use disorders (SUDs) frequently co-occur. For instance, among individuals seeking treatment for 
substance use disorder, approximately $36 \%$ to $50 \%$ meet criteria for lifetime PTSD. ${ }^{7}$

In the study by Guelen and his colleques ${ }^{8}$, among SUD patients, $36.6 \%$ scored positive on current PTSD. In the control group $10.2 \%$ were diagnosed with PTSD. There was a statistically significant relation between SUD and whether or not a person scored positive on PTSD $\chi^{2}=48.09, p<0.001$. They found that based on odds ratio individuals are 5.27 times more likely to score positive on PTSD if they are patients with SUD than if they are not patients with SUD. Other studies found that approximately half of individuals seeking treatment for SUD meet current criteria for PTSD. ${ }^{9}$

Rates of PTSD appear to be higher among patients in in-patient substance abuse treatment (up to $42.5 \%)^{10}$.

Studies have reported a general lack of assessment for or recognition of PTSD by clinicians. Dansky et $\mathrm{al}^{11}$ found that a research interview identified $40 \%$ more PTSD cases than did chart diagnosis of patients assessed for a substance abuse treatment programme.

\section{Materials and methods}

\section{Study setting}

The Centre for Addiction Treatment and Research (CATR) Vom is located within the premises of Vom Christian Hospital and was established through collaboration between Church of Christ in Nations (COCIN) and Jos University Teaching Hospital. The centre receives patients mainly from within Plateau state but also from neighboring states of Bauchi, Gombe, Kaduna, Nassarawa and Federal Capital Territory.

\section{Study population}

All patients on admission during the study period

\section{Study design.}

This was a cross sectional study of patients on admission at CATR Vom in June 2017

\section{Sample size,}

All patients on admission during the period of the study were included.

\section{Inclusion/exclusion criteria,}

All patients on admission at the CATR Vom in June, 2017 who consented to participate were included. The patients who did not consent to participate were excluded.

\section{Ethical consideration}

Ethical permission was obtained from the management of CATR Vom

\section{Data collection}

After obtaining informed consent, the patients on admission during the study period were administered the PTSD check list (PCL). ${ }^{12}$ The PCL is a 17 - item self report questionnaire in which respondents rate traumatic symptoms they experienced in terms of frequency/severity on a Likert- type scale ranging from the least i.e. $1=$ not at all; to the most severe i.e. $5=$ extremely. It measures the 17 DSM IV-TR symptoms of PTSD. It serves as an instrument for screening and diagnosis of PTSD. The scores range from 17 to 85 and a diagnosis is made by determining whether an individual met DSM-IV-TR symptom criteria for PTSD. The PCL is an easily administered self-report rating scale for assessing the symptoms of PTSD. It has excellent test-retest reliability (.96) .The item-scale total correlations range from .62 to .87 . Its internal consistency is very high (.97 for all 17 symptoms). The PCL correlates strongly with other measures of PTSD, such as the Mississippi Scale, the PK scale of the MMPI-2, and the Impact of Event Scale. ${ }^{13}$ Socio demographic, substance use and other relevant data was collected from the patients' case notes.

\section{Data analysis}

Statistical analysis was performed using the Statistical Package for the Social Sciences version 17.0 software for Windows (SPSS Inc., Chicago, IL, USA). Categorical data were presented as absolute values and $(\%)$. Continuous data were presented as median and range. A $P$-value of $<0.05$ was considered statistically significant.

\section{Results}

A total of 38 respondents were analyzed. Majority 35 $(92 \%)$ were males and only $3(8 \%)$ were females. The patients were mainly young (mean age + SD of $25.8 \pm$ 4.6 years), and single 27 (71.05\%). The patients were found to be fairly well educated. All of them had formal education, $12(31.6 \%)$ had primary education, $19(50 \%)$ had secondary education, while 7 (18.4\%) had tertiary education. The average number of years spent in school was $10.8 \pm 3.7$ years.

The patients were found to have been using psychoactive substances for a long time, the mean 
duration $+\mathrm{SD}$ of substance use was $14.3 \pm 6.3$ years. The least duration was 1 year while the longest duration was a 30 year history of alcohol use reported by a 47 year old patient.

Cannabis, Alcohol and opiates mainly Tramadol were the commonest substances of abuse. As a group, CNS stimulants (tramadol, codeine, cigarette, caffeine), were the most commonly abused drugs followed by sedatives (alcohol, rohypnol, diazepam). The entire group were poly substance abusers with 4 $(10.5 \%)$ of the patients abusing up to 8 different psychoactive substances cutting across various groups eg stimulants, sedatives and others .

Although a good number of the respondents 8 $(21.05 \%)$ were still in school (students), Unemployment was very high among the SUDs with $22(57.8 \%)$ of them being unemployed and only 3 (7.8\%) were in formal employment as civil servants.

When the patients responses on the PTSD check list questionnaires (PCL) were analyzed, 8 (21\%) of them met the DSM-IV TR criteria for the diagnosis of PTSD. Therefore, the prevalence of PTSD in these SUD in-patients is $21 \%$.

The SUD/PTSD patients appeared to be quite similar to the SUD/no PTSD patients. No significant differences were found with regard to their gender $\chi^{2}$ $(1)=2.186, p=0.376$ primary substance $\chi^{2}(4)=2.584$, $p=0.812$ and previous admissions $\chi^{2}(3)=3.715$, $p=0.286$.

Table 1. Sociodemographic characteristics of the patients

\begin{tabular}{lll}
\hline Sociodemographic profiles of patients & Variable & no \\
\hline Gender & Male & 92 \\
& Female & 8 \\
Age (years) & Range & $18-57$ \\
& Mean (SD) & $25.8(4.6)$ \\
Marital status & Single & 71.05 \\
& Married & 21.05 \\
& Divorced & 2.63 \\
Occupation & Separated & 5.26 \\
& & \\
& Unemployed & 57.89 \\
& Student & 21.05 \\
Religion & Civil servant & 7.89 \\
& Private employment & 13.16 \\
& Christianity & 84.2 \\
\hline
\end{tabular}

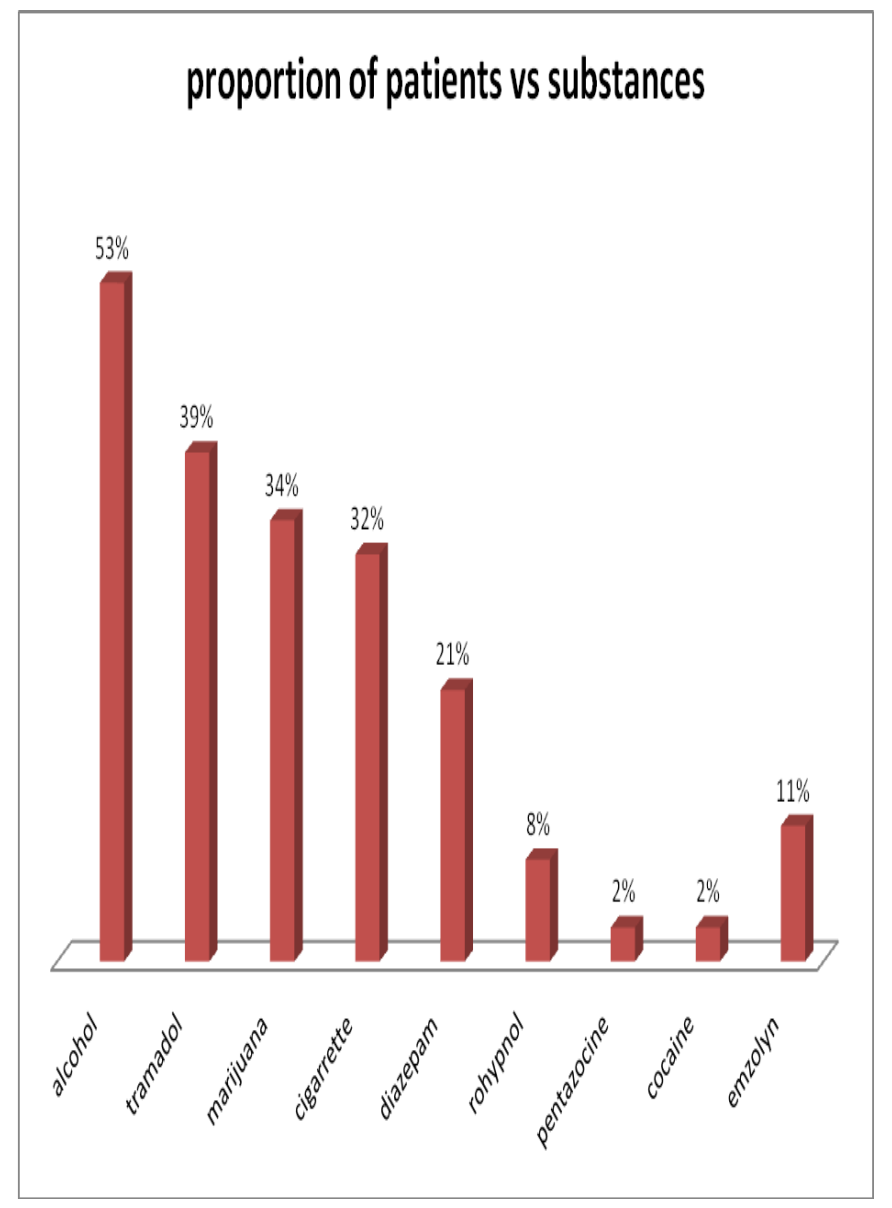

Figure 1. Rates of abuse of substances by respondents 
Table 2. Relationship between PTSD and respondents' characteristics

\begin{tabular}{|c|c|c|c|c|c|}
\hline & SUD $(N=38)$ & PTSD $(N=8)$ & no PTSD $(N=30)$ & Statistics & Significance \\
\hline \multicolumn{6}{|l|}{ Demographics } \\
\hline Mean age (SD) & $25.8(4.6)$ & $27.9(8.9)$ & $26.3(7.8)$ & $U=1970, r=0.04$ & 0.390 \\
\hline \multicolumn{6}{|l|}{ Gender (\%) } \\
\hline Male & 92.1 & 87.5 & 93.33 & $\chi^{2}(1)=2.186$ & 0.376 \\
\hline Female & 7.9 & 12.5 & 6.67 & & \\
\hline \multicolumn{6}{|c|}{ Primary substance $(\%)$} \\
\hline Alcohol & 31.58 & 37.5 & 30.00 & $\chi^{2}(4)=2.584$ & 0.812 \\
\hline Tramadol & 34.21 & 25.0 & 33.33 & & \\
\hline Cannabis & 26.32 & 25.0 & 20.00 & & \\
\hline Benzodiazepines & 5.26 & 12.5 & 13.33 & & \\
\hline Not sure & 2.63 & 0.0 & 3.33 & & \\
\hline \multicolumn{6}{|c|}{ Previous admissions (\%) } \\
\hline None & 28.95 & 12.5 & 21.67 & $\chi^{2}(3)=3.715$ & 0.286 \\
\hline $1-2$ & 42.11 & 62.5 & 46.67 & & \\
\hline $3-4$ & 21.85 & 25.0 & 20.00 & & \\
\hline 5 or $>$ & 2.6 & 0.0 & 6.67 & & \\
\hline
\end{tabular}

\section{Discussion}

A substantial proportion of the patients (21\%) overall met the criteria for the diagnosis of PTSD when assessed using the PCL questionnaire (civilian version). Separating both genders however, we found that only $20.0 \%$ of males had PTSD while $33.3 \%$ of the females had PTSD. In a previous study, Brown and his colleagues ${ }^{14}$ studied 84 patients (48 male and 36 female) admitted for detoxification at a private hospital. They found that $43 \%$ of women and $12 \%$ of men met criteria for PTSD based on the civilian version of the Mississippi scale. Although our sample is less than the sample studied by Brown et al, the findings were somewhat similar with more females having PTSD than males. This study highlights the comorbidity that exists between substance abuse and PTSD. There was a high unemployment rate among the SUDs with $58 \%$ of them being unemployed. An overwhelming majority of the patients were Christians as shown in table 1 . This may not be unconnected with the population of the state which is a predominantly Christian state. We found out that the patients have been using the substances for a very long time with an average duration of 14.3 years of psychoactive substance use. This reflects the gradual progression of SUD which may take several years for the patient to develop dependence and the subsequent mental/psychological disorders which eventually prompt the SUD patient to seek treatment. Multiple psychoactive substance use was recorded in all the respondents with one patient using 8 different psychoactive substances.

Majority of the patients have acquired an appreciable level of education with an average of 10.8 years of school. The PTSD and no PTSD patients were essentially similar. There was no significant difference in their educational status, duration of substance use as well as their marital statuses.

The fact that many SUD patients score positive on PTSD has important implications for clinical practice. At present, PTSD receives little attention in SUD treatment ${ }^{15}$ and systematically conducted screening with a validated questionnaire does not take place in more than $80 \%$ of SUD patients. ${ }^{16}$

It is therefore not surprising that PTSD remained largely undetected when no standardized tool was used. These findings are important because they draw attention to the fact that, with regard to the diagnosis of PTSD, SUD treatment facilities should not solely rely on the opinions of clinicians and interviewers. Clinical judgment is prone to bias and, when possible, validated assessment tools should be used. ${ }^{17}, 18$ Our study was carried out on inpatients on treatment for substance dependence. Another way of studying this co morbidity is to assess for substance use disorders among patients who are primarily admitted for PTSD. In some of such studies, Boudewyns et al ${ }^{19}$ 
reported that $91 \%$ of their inpatient PTSD sample met lifetime criteria for a substance use disorder. Similarly, in a large study of 5,338 veterans seeking treatment within the Department of Veterans Affairs specialized outpatient PTSD programs, Fontana et al. reported that $44 \%$ met criteria for alcohol abuse/dependence and $22 \%$ for drug abuse/dependence. ${ }^{20}$

It has been postulated that both PTSD and substance abuse can occur as a complication of previous trauma in individuals. Brady, et al Studied female substance abuse patients, 30 of whom had PTSD and 25 of whom did not. They found that Women with PTSD were more likely than women without PTSD to have experienced sexual and physical abuse, especially during childhood. They were also found to be more symptomatic and less compliant with aftercare. ${ }^{21}$

In search for possible reasons why PTSD and substance abuse occur commonly together, recent studies suggest that strong relationships exist between PTSD and alcoholism. ${ }^{22}$ In particular, central catecholamine and endogenous opioid systems have been implicated both in this syndrome (PTSD) and in substance abuse. ${ }^{23}$

Amaro et $\mathrm{al}^{24}$ as well as Van Dam and colleagues ${ }^{25}$ showed that SUD patients with co morbid PTSD may benefit from parallel treatment of their PTSD and patients are denied a potentially more favourable treatment outcome when their PTSD remains undiagnosed. ${ }^{26}$

Because these two disorders occur commonly together, difficulties exist in assessing and treating comorbid PTSD and substance abuse. ${ }^{27} \mathrm{~A}$ behavioral model for treating substance abuse in PTSD has been postulated. This treatment process is conceptualized as consisting of five stages, each of which has specific goals. This treatment process encompasses direct therapeutic exposure, problem-solving skills training, and relapse prevention among other processes. ${ }^{28}$ applying this behavioral model for treatment of these co-morbid disorders in our patients is expected to improve their treatment outcome.

\section{Conclusion}

PTSD occurs commonly as a co-morbid disorder with substance use disorder (SUD). This dual diagnosis remains a challenge as PTSD remains largely undiagnosed in a substantial number of our inpatients.

\section{Recommendation}

A routine screening for PTSD using instruments such as PCL $-\mathrm{C}$ in SUD in-patients is recommended.

\section{Study limitation}

The possibility of recall bias among in-patients when asked to recall traumatic events that may have happened to them in the past was a major limitation.

\section{Acknowledgement}

We are grateful to the management of Centre for Addiction treatment and research Vom, as well as the patients.

\section{Financial support and sponsorship}

Nil

\section{Conflict of interests}

The authors declare no conflict of interests.

\section{References}

1. American Psychiatric Association. Diagnostic and Statistical Manual of Mental Disorders. 4th Edition. Washington, DC: American Psychiatric Press; 1994.

2. Da Costa JM. On irritable heart: a clinical study of a form of functional cardiac disorder and its consequences. Am J Med Sci. 1871; 61:17-52.

3. Viewig VR, Julius DA, Fernandez A, Beaty-Brooks M, Hettema JM, Pandurangi AK: Post traumatic stress disorder: clinical features, pathophysiology and treatment. The American Journal of Medicine. Doi: https://doi.org/10.1016/jamjamed/2015.

4. Bonin M. F, Norton G. R, Asmundson G. J. G, Dicurzio S, Pidlubney S. Drinking away the hurt: The nature and prevalence of PTSD in substance abuse patients attending a community-based treatment program. J Behav Ther Exp Psychiat. 2000;31(1):5566.

5. Driessen M, Schulte S, Luedecke C, Schaefer I, Sutmann F, Ohlmeier M, et al. Trauma and PTSD in patients with alcohol, drug, or dual dependence: A multi-center study. Alcoholism: Clin Exp Res. 2008;32(3):481-488.

6. Kessler RC, Sonnega A, Bromet E, Hughes M, Nelson CB: Posttraumatic stress disorder in the National Co morbidity Survey. Arch Gen Psychiat. 1995; 52:10481060

7. Brady KT, Back SE, Coffey SF. Substance abuse and post traumatic stress disorder. Current directions in psychological science. October 2004; vol. 13 no. 5: 206-209. 
8. Guelen N, Havermans RC, Tekelenburg M, Jansen A: Prevalence of post traumatic stress disorder among patients with substance use disorder: It is higher than clinicians think it is. Eur J Traumatol. 2012. 3;10: 3402/ejpt. v3i0.17734 . Published online in August 2012.doi.10:3402/ejpt.v3i0.17734.PMCID;PMC34156 09.

9. Brady KT, Back S, Coffey SF. Substance abuse and posttraumatic stress disorder. Curr Dir Psychol Sci. 2004;13:206-9

10. Dansky BS, Saladin ME, Brady KT, Kilpatrick DG, Resnick HS: Prevalence of victimization and posttraumatic stress disorder among women with substance use disorders: comparison of telephone and in-person assessment samples. Int $\mathrm{J}$ Addict 1995; 30:1079-1099.

11. Dansky, B.S., Roitzsch, J.C., Brady, K.T., Saladin, M.E. Posttraumatic stress disorder in the community: An epidemiological study. Psychol. Med. 1997; 21: 713-721.

12. Sundin C: Horowitz M. Impact of events scale. Psychometric properties. Br. J Psychiat. 2002; 180:205-209.

13. Weathers, F., Litz, B., Herman, D., Huska, J., \& Keane, T. (October 1993). The PTSD Checklist (PCL): Reliability, Validity, and Diagnostic Utility. Paper presented at the Annual Convention of the International Society for Traumatic Stress Studies, San Antonio, TX

14. Brown, P.J., Recupero, P.R., \& Stout, R. PTSD substance abuse comorbidity and treatment utilization. Addictive Behaviors, 1995; 20: 251-254

15. Najavits L. M, Sullivan T. P, Schmitz M, Weiss R. D, Lee C. S. N. Treatment utilization by women with PTSD and substance dependence. Am J Addict. 2004;13:215-224.

16. Young H. E, Rosen C. S, Finney J. W. A survey of PTSD screening and referral practices in VA addiction treatment programs. J Subst Abuse Treat. 2005;28:313-319

17. Dawes R. M, Faust D, Meehl P. E. Clinical versus actuarial judgment,. Science. 1989; 243(4899):16681674.

18. Garb H. N. Clinical judgment and decision making. Annu Rev Clin Psychol. 2005; 1:67-89.

19. Boudewyns, P. A., Woods, M. G., Hyer, L., and Albrecht, J. W. Chronic combat-related PTSD and concurrent substance abuse: implications for treatment of the frequent "dual diagnosis."J. Traum. Stress 1991; 4(4): 549-560.

20. Fontana, A., Rosenheck, R., Spencer, H., \& Gray, S. The long journey home IV: The fourth progress report on the Department of Veterans Affairs specialized PTSD programs. 1995. West Haven, Connecticut: Department of Veterans Affairs, Northeast Program Evaluation Center.

21. Brady, K.T., Killeen, T., Saladeen, M.E., Dansky, B.S., \& Becker, S. Comorbid substance abuse and posttraumatic stress disorder: Characteristics of women in treatment. Am J Addictions, 1994; 3: 160-164.

22. Stewart, S.H. Alcohol abuse in individuals exposed to trauma: A critical review. Psychol. Bulletin, 1996; 120,83-112.

23. Kosten, T.R. \& Krystal, J.H. Biological mechanisms in posttraumatic stress disorder: Relevance for substance abuse. In M. Galanter (Ed.), recent developments in alcoholism, 1988; Vol. 6 (pp. 49-68). New York: Plenum.

24. Amaro H. dai J, Arevalo S, Acevedo S, Matsumoto A, Nieves R, Prado G. 22 Effects of integrated trauma treatment on outcome in a racially/ethnically diverse sample of women in urban community-based substance abuse treatment. J urban health., 2007Jul 84(4) 508-22

25. Van Dam D, Vedel E, Ehring T, Emmelkamp P. M. G. Psychological treatments for concurrent posttraumatic stress disorder and substance use disorder: A systematic review. Clin Psychol Rev. 2012;32:202-214

26. Mills K. L, Teesson M, Ross J, Darke S, Shanahan M. The costs and outcomes of treatment for opiod dependence associated with post traumatic stress disorder. Psychiatr Serv. 2005; 56:940-945.

27. Jelinek, J.M. \& Williams, T. Post-traumatic stress disorder and substance abuse in Vietnam combat veterans: Treatment problems, strategies, and recommendations. Journal of Substance Abuse Treatment, 1984; 1: 87-97.

28. Abueg, F.R. \& Fairbank, J.A. Behavioral treatment of posttraumatic stress disorder and co-occurring substance abuse. In P.A. Saigh (Ed.), Posttraumatic stress disorder: A behavioral approach to assessment and treatment 1992. (pp. 111-146) Boston: Allyn \& Bacon. 